Article

\title{
Evaluation of US EPA Method 3052 Microwave Acid Digestion for Quantification of Majority Metals in Waste Printed Circuit Boards
}

\author{
Dagmar Remeteiová, Silvia Ružičková *, Vladislava Mičková, Martina Laubertová \\ and Róberta Slezáková
}

Institute of Recycling Technologies, Metallurgy and Recycling, Faculty of Materials, Technical University of Košice, Letná 9, 04200 Košice, Slovakia; dagmar.remeteiova@tuke.sk (D.R.); vladislava.mickova@tuke.sk (V.M.); martina.laubertova@tuke.sk (M.L.); roberta.slezakova@tuke.sk (R.S.)

* Correspondence: silvia.ruzickova@tuke.sk

Received: 16 October 2020; Accepted: 11 November 2020; Published: 13 November 2020

\begin{abstract}
Metal content determination is one of the critical aspects of preparing electronic waste for metal recycling. In spite of the fact that end-of-life printed circuit boards are considered to be a secondary resource reservoir, no standard procedure exists for determining the total metal content in this heterogeneous multicomponent material containing plastics, metals, alloys and ceramics. We investigated the utilization of United States Environmental Protection Agency (US EPA) microwave acid digestion (Method 3052) and various modifications of this procedure for effective releasing of $\mathrm{Cu}$, $\mathrm{Fe}, \mathrm{Ni}, \mathrm{Pb}$ and $\mathrm{Zn}$ from waste printed circuit boards (WPCBs) from mobile phones. The maximum contents of $\mathrm{Cu}(22.6 \mathrm{wt} . \%), \mathrm{Fe}(5.0 \mathrm{wt} . \%), \mathrm{Ni}(2.0 \mathrm{wt} . \%)$ and $\mathrm{Zn}(2.6 \mathrm{wt} . \%)$ were obtained using the standard (unmodified) US EPA 3052 digestion procedure, but the total digestion of PCB material was not achieved. The solid residue material after digestion by means of the US EPA 3052 method consisted predominantly of oxides $(\mathrm{Ca}, \mathrm{Mg}$ and $\mathrm{Al})$ and fluorides ( $\mathrm{Ca}$ and $\mathrm{Mg}$ ), and some particles contained minor amounts of $\mathrm{Fe}$ and $\mathrm{Cu}$.
\end{abstract}

Keywords: waste electrical and electronic equipment; printed circuit boards; acid microwave digestion; HR CS FAAS; heavy metals

\section{Introduction}

Older mobile phones types typically consist of electronic circuitry, a printed circuit board (PCB), a liquid crystal display, a battery, a keypad and a plastic case [1]. The waste PCBs (WPCBs) are diverse and complex in terms of their type, size, shape, components and composition [2]. The elemental composition of PCBs varies depending on their type and applications [3]. In general, these PCBs contain, in terms of weight, approximately $40 \%$ metals, $30 \%$ plastics or polymers, and $30 \%$ ceramics or refractory metal oxides [1,2,4-6]. The majority metals in PCBs are $\mathrm{Cu}, \mathrm{Pb}, \mathrm{Zn}, \mathrm{Fe}, \mathrm{Ni}$ and $\mathrm{Sn}$ [7]. Metallic material contains various elements, including precious metals, but also different hazardous elements such as heavy metals [3]. Three main types of recyclable materials can be retrieved from PCBs: metals (mainly $\mathrm{Cu}, \mathrm{Al}, \mathrm{Sn}$ and $\mathrm{Pb}$ ) and precious metals ( $\mathrm{Au}, \mathrm{Ag}$ and $\mathrm{Pt}$ ), polymeric materials and ceramic materials [8]. Each metal occurring in PCBs has its own specific properties depending on the particular point of view, such as weight share, economic value, environmental impacts, or natural resources depletion [9].

The results of quantitative analysis of highly heterogeneous materials such as e-waste may be influenced by uncertainties stemming from several sources, for example, sampling, digestion, dilution, calibration or other interferences [10]. 
The success of e-scrap treatment depends largely on the quality of sampling and assaying. Professional sampling and analysis is the basis for proper material assessment. Most sampling and assaying processes and technologies are still in-house developed [11-15]. The general procedure in preparing samples from WPCBs involves crushing them into smaller particles (less than $1 \mathrm{~mm}$ in size), followed by various techniques, including magnetic, electrostatic, electrowinning and selective dissolution in order to separate the components [16,17].

The effectivity of acid digestion reaction with solid waste material depends on several factors: the character and concentration of the acid used, the reaction time, external driving forces (heat, ultrasound, agitation and microwaves), and reaction conditions (especially temperature and solid-liquid ratio) [4]. The choice of acid or acid mixture for digestion largely depends on the metal forms present in the waste $[4,18]$. For example, hydrochloric acid is usually applied to release metals associated with carbonates, phosphates, borates and some oxides and sulphides [18], and metals bound to silicate fractions are dissolved by hydrofluoric acid $[4,18]$. The mixture of $\mathrm{HNO}_{3}+\mathrm{HF}$ provides the strongest chemical interaction and dissolving power, and the combination of $\mathrm{HNO}_{3}$ with microwave (MW) energy also represents a high-energy system, with the result that both of these systems may lead to complete dissolving of any matrix [10]. The use of an aggressive combination of $\mathrm{HNO}_{3}+\mathrm{HF}+\mathrm{MW}$ energy has been found to be more effective in releasing the majority metals $\mathrm{Cu}, \mathrm{Fe}, \mathrm{Ni}$ and $\mathrm{Zn}$ from WPCBs, compared with the utilization of hot aqua regia digestion.

The United States Environmental Protection Agency (US EPA) Solid Waste 846 Method 3052 is applicable to the microwave wet acid digestion of solid waste materials with siliceous, organics and other complex matrices [4]. This US EPA method employs conc. $\mathrm{HNO}_{3}$ and conc. HF, and this mixture combined with MW energy creates a high energy system with strongest chemical interaction, oxidization and dissolving power [10].

Although this method was not originally designed for PCBs, it has already been used for this type of material (IT, telecommunication, large household, consumer equipment and lighting equipment) $[7,19,20]$.

In our study, we decided to use a new approach based on the application of the original US EPA Method 3052 and its modifications to material from older mobile phone type PCBs in order to select the most effective digestion method. The effectivity of MW digestion procedures for releasing the majority elements $(\mathrm{Cu}, \mathrm{Pb}, \mathrm{Zn}, \mathrm{Fe}$ and $\mathrm{Ni})$ from PCBs was monitored through determination of their content in the solution after digestion by means of high-resolution continuum-source flame atomic absorption spectrometry (HR CS FAAS).

\section{Materials and Methods}

\subsection{Equipment}

Digestion tests on PCB material were carried out using an Ethos One pressurised closed-vessel laboratory microwave (MW) oven (Milestone Systems Italia Srl., Cinisello Balsamo, Italy), which ensures uniform distribution of MW radiation. The system was equipped with a high-pressure ten-position segmented rotor (SK-10), consisting of nine standard segments and one reference segment for temperature control. The digestion vessels, made from chemically-modified PTFE, were cleaned using $10 \mathrm{~cm}^{3}$ conc. $\mathrm{HNO}_{3}$, heated for $15 \mathrm{~min}$ at $180^{\circ} \mathrm{C}$ and rinsed with ultrapure water before each series of experiments.

The metals content in the solutions after individual digestion procedures was determined using the HR-CS FAAS method on a contrAA 700 spectrometer (Analytik Jena AG, Jena, Germany), which is operated by ASpect CS software. The most suitable working conditions for effective AAS measurements (fuel flow and burner height) were experimentally determined prior to the analyses using a calibration solution with the highest content of a particular element. The operating conditions of the HR-CS FAAS method, including wavelength, fuel (acetylene) flow, burner height and concentration of metals in the calibration solutions, are shown in Table 1. 
Table 1. Operating conditions of high-resolution continuum-source flame atomic absorption spectrometry (HR CS FAAS) for element analysis.

\begin{tabular}{ccccc}
\hline Element & $\begin{array}{c}\text { Wavelength } \\
{[\mathbf{n m}]}\end{array}$ & $\begin{array}{c}\text { Fuel Flow } \\
{\left[\mathbf{d m}^{\mathbf{3}} \mathbf{h}^{-\mathbf{1}}\right]}\end{array}$ & $\begin{array}{c}\text { Burner Height } \\
{[\mathbf{m m}]}\end{array}$ & $\begin{array}{c}\mathbf{c}_{\text {Me in Calibration }} \\
\text { Solution }\left[\mathbf{m g ~ d m}^{-3}\right]\end{array}$ \\
\hline $\mathrm{Cu}$ & 324.7840 & 50 & 6 & $0.1,0.5,1.0,2.0,4.0$ \\
$\mathrm{Fe}$ & 248.3270 & 60 & 8 & $0.5,1.0,2.0,4.0,8.0$ \\
$\mathrm{Zn}$ & 213.8570 & 50 & 6 & $0.1,0.2,0.4,1.0$ \\
$\mathrm{Ni}$ & 232.0030 & 45 & 7 & $0.2,0.4,1.0,4.0,8.0$ \\
$\mathrm{~Pb}$ & 217.0005 & 65 & 6 & $0.5,1.0,5.0,10.0$ \\
\hline
\end{tabular}

The morphology (surface topography) of the solid residue after the most effective MW digestion procedure was determined by means of scanning electron microscopy (SEM) on an FE SEM MIRA 3 microscope (TESCAN, Brno, Czech Republic). The local surface elemental composition was examined using energy-dispersive X-ray spectroscopy (EDX) on an EDX microanalysis system (Oxford Instruments, Oxford, UK). The SEM EDX analysis was carried out at the Institute of Materials Research of Slovak Academy of Sciences, Košice. The ultrapure water for the solutions and cleaning operations was prepared using an Elga Labwater deionizer.

\subsection{Reagents, Standards and Material}

All the chemicals used were of analytical grade. The reagents for MW digestion were purchased from Fischer Chemical, UK and Centralchem, Czech Republic and included concentrated nitric acid (conc. $\mathrm{HNO}_{3}, 65 \% w / w$ ), concentrated hydrochloric acid (conc. $\mathrm{HCl}, 37 \% w / w$ ) and concentrated hydrofluoric acid (conc. HF, 40\% w/w). Calibration solutions for the HR-CS FAAS method were prepared by diluting standard solutions of $\mathrm{Cu}, \mathrm{Fe}, \mathrm{Ni}, \mathrm{Pb}$ and $\mathrm{Zn}$ (SIGMA-ALDRICH Co. LLC., St. Louis, MO, USA) with a solution of $\mathrm{HCl}(1 \% v / v)$ in ultrapure water. All laboratory flasks were washed with dilute $\mathrm{HNO}_{3}\left(4 \mathrm{~mol} \mathrm{dm}^{-3}\right)$, followed by rinsing with ultrapure water.

The PCB material (analytical samples) for all MW digestion experiments was obtained by processing approx. $80 \mathrm{~kg}$ of end-of-life mobile phones with various years of production and from various manufacturers. Batteries and plastic covers from the mobile phones were removed by hand. The remaining PCBs from the mobile phones (Figure 1a) were used for the experiments. Their total weight was $2 \mathrm{~kg}$. The crushing operation was carried out with a crusher hammer down to fraction $\mathrm{d} \leq 8.0 \mathrm{~mm}$, and the crushed PCBs were homogenized. A sample of $1 \mathrm{~kg}$ was obtained by hand quartering, which was then divided three times with a mechanical divider. Magnetic separation was carried out to remove the magnetic fraction from the sample. Then, eight representative samples were milled separately in a hammer mill, combined to fraction $\mathrm{d} \leq 1.0 \mathrm{~mm}$ and sieved in order to obtain the final PCB analytical sample for experiments $(\mathrm{d} \leq 0.5 \mathrm{~mm}$ ) (Figure $1 \mathrm{~b}$ ).

\subsection{Microwave-Assisted Digestion Procedures}

For quantitative metal liberation assessment, the sample of PCBs was subjected to four MW digestion procedures at $180^{\circ} \mathrm{C}$ :

Method A1-the original US EPA Method 3052. In this digestion procedure, a $0.25 \mathrm{~g}$ PCB sample was digested in $4.5 \mathrm{~cm}^{3}$ conc. $\mathrm{HNO}_{3}$ and $1.5 \mathrm{~cm}^{3}$ conc. HF for $10 \mathrm{~min}$. Method A2-the US EPA Method 3052 with extension of digestion time to $20 \mathrm{~min}$. Method A3-the US EPA Method 3052 with extension of digestion time to $30 \mathrm{~min}$. 


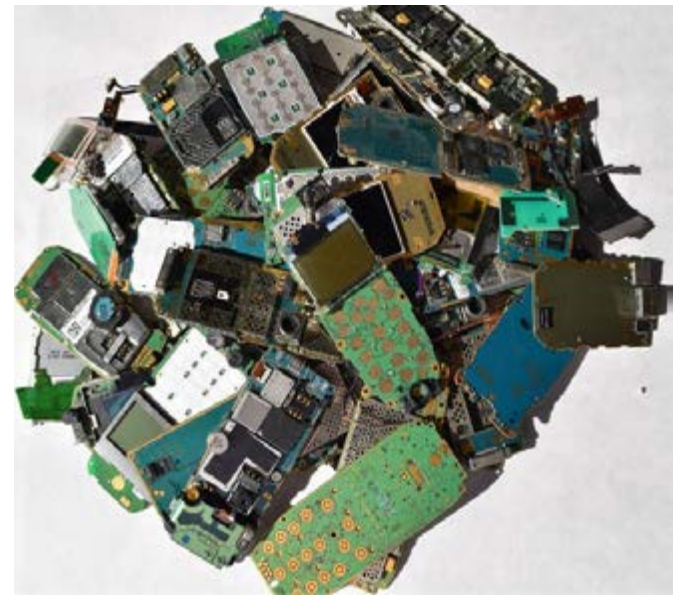

(a)

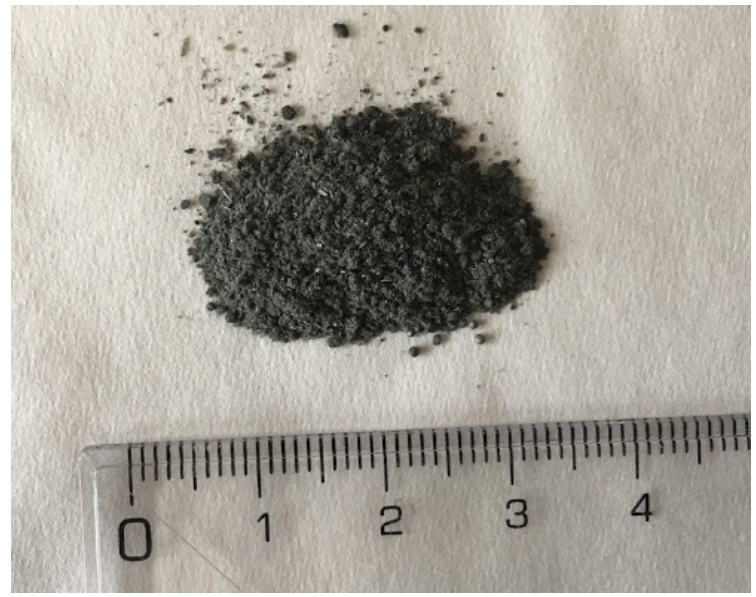

(b)

Figure 1. (a) Printed circuit boards (PCBs) of mobile phones; (b) analytical sample of PCBs (photos taken by author).

Method B - an adapted US EPA Method 3052. This digestion procedure consisted of two steps. In the first step, a $0.25 \mathrm{~g}$ PCB sample was digested in $4.5 \mathrm{~cm}^{3}$ conc. $\mathrm{HNO}_{3}$ and $1.5 \mathrm{~cm}^{3}$ conc. $\mathrm{HF}$ for $10 \mathrm{~min}$. In the second step, the MW digestion was stopped and the vessels were opened to release the reaction gases, and then after closing of the vessels the digestion continued for a period of $10 \mathrm{~min}$.

Method C—an adapted US EPA Method 3052. This digestion procedure included two steps as well. In the first step, a $0.2 \mathrm{~g}$ PCB sample was digested in $9.0 \mathrm{~cm}^{3}$ conc. $\mathrm{HNO}_{3}$ for $10 \mathrm{~min}$ with the aim of decomposing the organic (plastic) material from the sample. In the second step, the digestion vessels were opened in order to release the reaction gases, and then after addition of $3.0 \mathrm{~cm}^{3}$ conc. HF and $3.0 \mathrm{~cm}^{3}$ conc. $\mathrm{HCl}$ (for digestion of inorganic materials) the vessels were closed and the digestion continued for a period of $10 \mathrm{~min}$.

Method D-an adapted US EPA Method 3052 [10]. In this digestion procedure, a $0.2 \mathrm{~g}$ PCB sample was digested in $9.0 \mathrm{~cm}^{3}$ conc. $\mathrm{HNO}_{3}$ and $3.0 \mathrm{~cm}^{3}$ conc. $\mathrm{HF}(60 \%$ abundance of reagents compared to the original US EPA method) for $10 \mathrm{~min}$.

After each digestion procedure, the content of the digestion vessels was filtered through quantitative filter paper into $100 \mathrm{~cm}^{3}$ volumetric flasks and supplemented with ultrapure water. These individual digestions performed with the aim of finding the most effective digestion procedure for complete release of selected elements from the PCB material were repeated four times, and analyses were carried out in triplicate. A summary of the complete procedural steps followed by sample digestion is schematically shown in Figure 2.

For statistical evaluation of the most effective digestion procedure, we performed ten repeated digestions. For elimination of the PCB material heterogeneity influence, we compared the contents of elements in $4 / 10$ replicates of the most effective digestion procedure in $4 / 10$ post-digestion solutions with their contents in the solution obtained by combining $4 / 10$ post-digestion residues. 


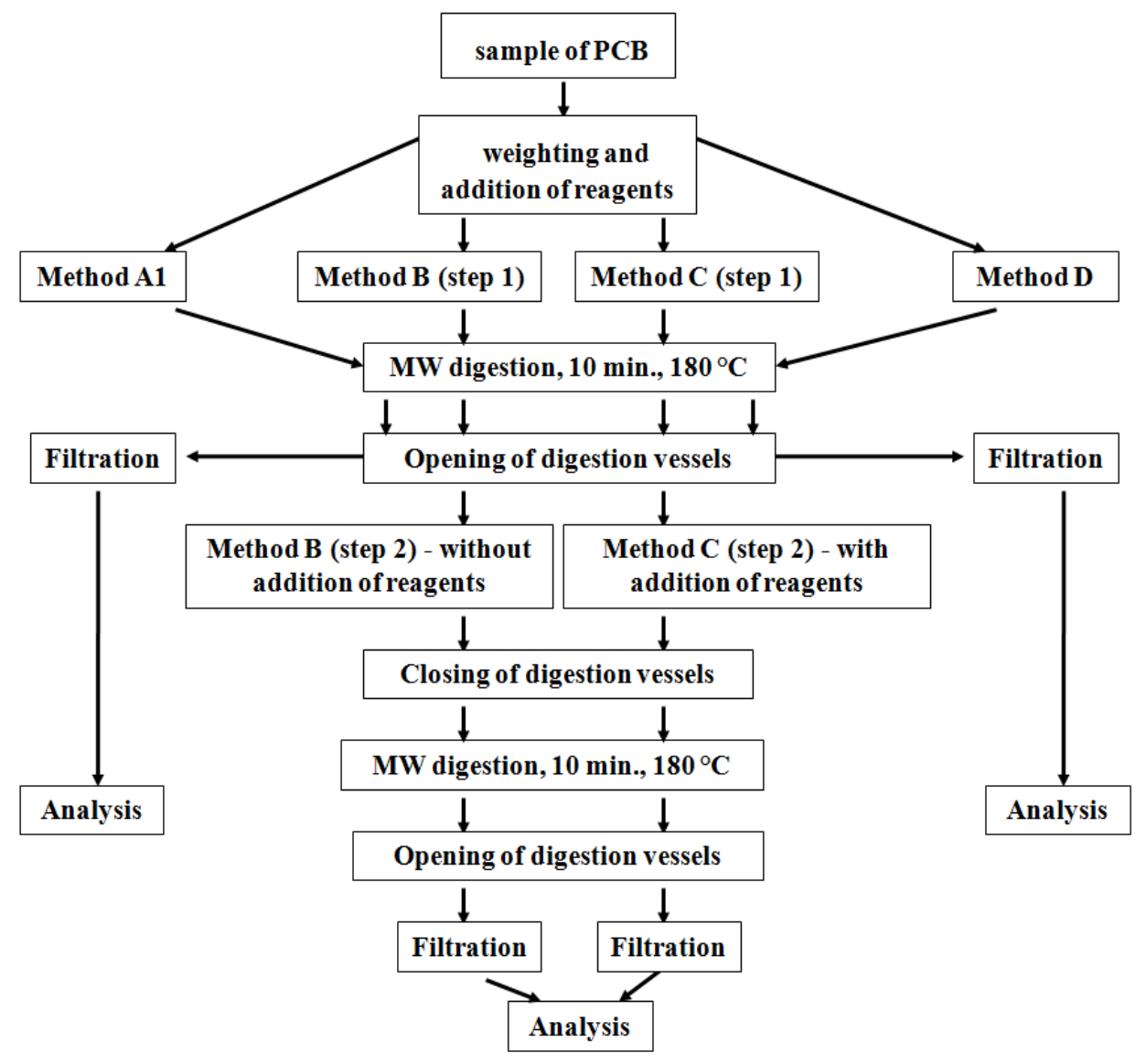

Figure 2. Block diagram of microwave (MW) digestion procedural steps.

\section{Results and Discussion}

In the first series of experiments, we monitored the effect of digestion time (10 min for method A1, 20 min for method A2 and 30 min for method A3) with application of the original US EPA Method 3052 on the release of elements into the post-digestion solutions. The results of these experiments are shown in Figure 3.

The results indicate that the extension of digestion time, with the exception of $\mathrm{Cu}$, does not influence the increase in content of elements in the solution after digestion, nor does it increase the effectivity of digestion. Decomposition for $30 \mathrm{~min}$ resulted in a $20 \%$ decrease in Cu recovery and up to a $60 \%$ decrease in Fe recovery. Although it is not possible expressly determine the reason for the decrease in decomposition efficiency by prolonging its decomposition time, it is most likely that the equilibrium of decomposition reactions were shifted due to excessive formation of reaction products. This result led us to apply Method B as a modification of the original US EPA Method 3052 in another series of experiments.

Our second series of experiments was focused on monitoring the effects of the three modifications of US EPA Method 3052 (Methods B, C and D) on the release of elements. The aim of the experiments was to shift the chemical balance to products of digestion reactions, which would lead to increased release of elements. The modifications of US EPA Method 3052 were as follows:

1. Opening digestion vessels to release gaseous products and repeating the digestion process in the second step (Method B);

2. Pre-digesting organic (plastic) materials with $\mathrm{HNO}_{3}$ in the first step (the most widely-used primary oxidant for the decomposition of organic matter [21]), and additing $\mathrm{HCl}$ and $\mathrm{HF}$ for digestion of inorganic materials in the second step (Method C), 
3. Increasing the $\mathrm{HNO}_{3}$ and $\mathrm{HF}$ amounts in the digestion mixture by about $60 \%$ (Method D) over the original US EPA method. The results of these experiments in comparison with results of the original US EPA Method 3052 (Method A1) are shown graphically in Figure 4.

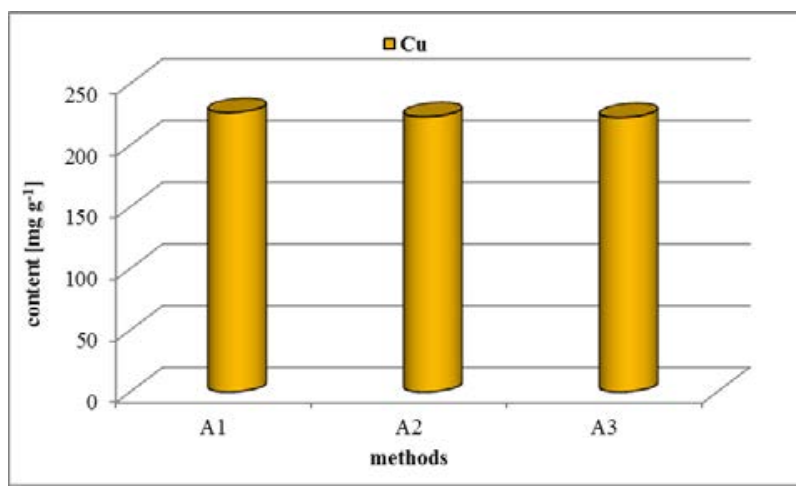

(a)

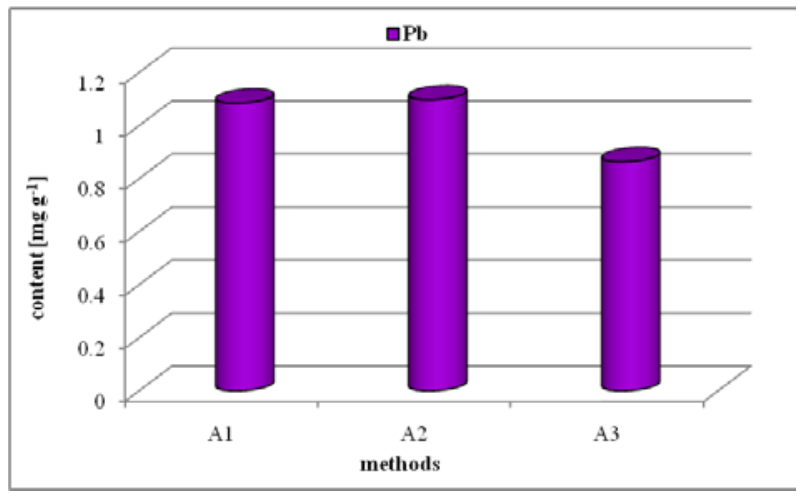

(b)

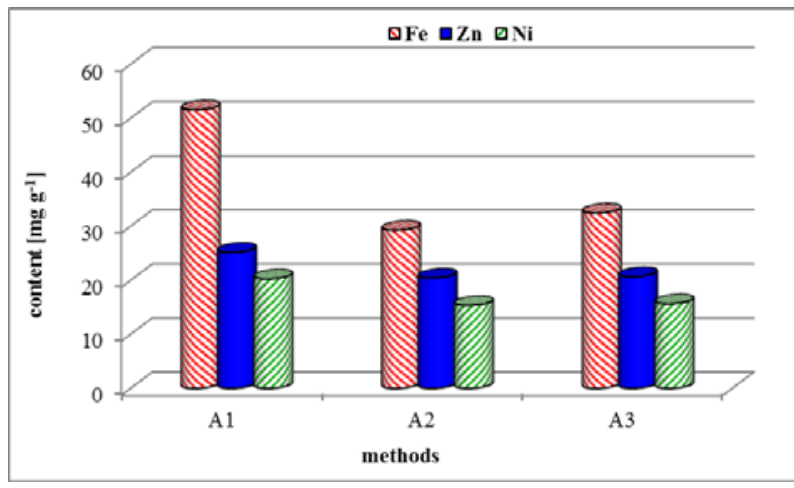

(c)

Figure 3. Content of $\mathrm{Cu}(\mathbf{a}), \mathrm{Pb}(\mathbf{b}), \mathrm{Fe}(\mathbf{c}), \mathrm{Zn}$ and $\mathrm{Ni}$ in post-digestion solutions obtained by application of the US EPA 3052 method (A1) and its modifications in time (A2, A3) on mobile phone PCBs. 


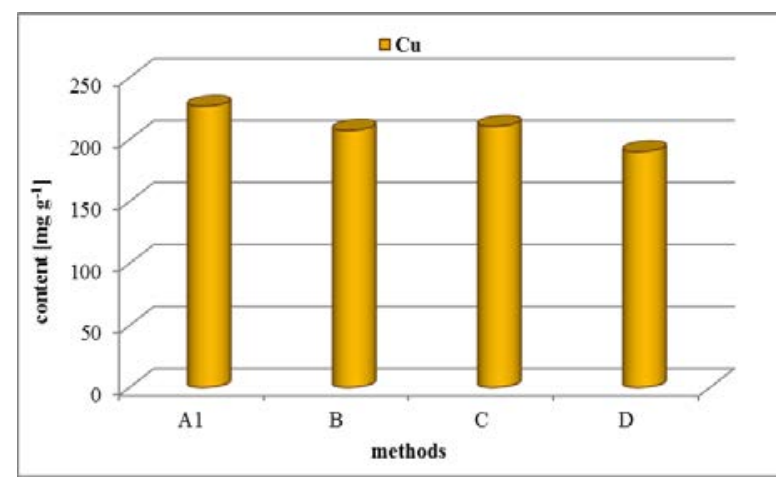

(a)

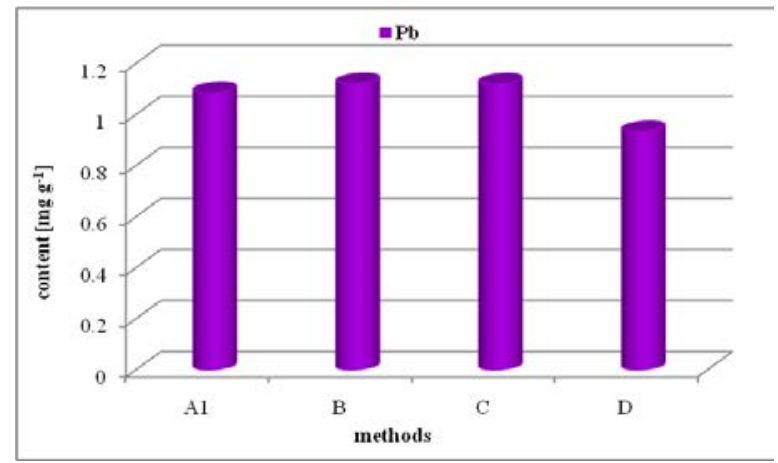

(b)

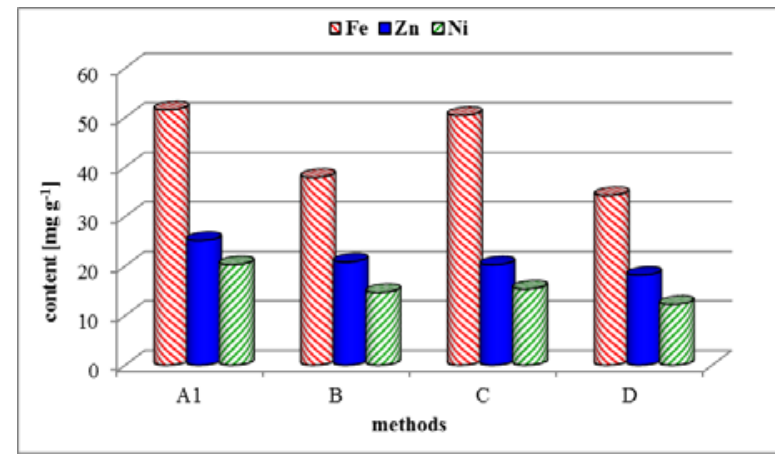

(c)

Figure 4. Content of $\mathrm{Cu}(\mathbf{a}), \mathrm{Pb}(\mathbf{b}), \mathrm{Fe}, \mathrm{Zn}$ and $\mathrm{Ni}(\mathbf{c})$ in post-digestion solutions obtained by application of the US EPA 3052 Method (A1) and its modifications in the number of digestion steps (B, C) and amount of reagents (D).

The results (Figure 4) show that application of the chosen digestion procedures did not achieve any increase in the release efficiency of metals from the PCB material in comparison with the original US EPA method. The efficiency of two-step decomposition with the addition of $\mathrm{HCl}$ in the second step was comparable to that of the US EPA method. Increasing the ratio of sample mass to digestion reagent volume appeared to be the least effective. Increasing the amount of reagents to the same amount of sample $(0.25 \mathrm{~g})$, in comparison to the original US EPA Method 3052, could result in an increase of the fluorides and oxides formation as new forms in the solid residue after digestion (see discussion in the last stage of studies).

The relative standard deviation (RSD) values, representing the uncertainty of elements content determination caused by the heterogeneity of the material, calculated from the four repeated digestions for each digestion method (A1, A2, A3, B, C and D) are shown in Table 2. 
Table 2. Relative standard deviation (RSD) values from four repeated digestions for each studied digestion method.

\begin{tabular}{ccccccc}
\hline \multirow{2}{*}{ Element } & \multicolumn{7}{c}{ RSD [\%] } \\
\cline { 2 - 7 } & A1 & A2 & A3 & B & C & D \\
\hline $\mathrm{Cu}$ & 5.879 & 5.952 & 5.501 & 5.481 & 12.35 & 6.410 \\
$\mathrm{Fe}$ & 15.33 & 17.63 & 20.56 & 18.97 & 14.32 & 18.09 \\
$\mathrm{Zn}$ & 7.672 & 4.981 & 8.530 & 6.689 & 18.95 & 20.48 \\
$\mathrm{Ni}$ & 16.04 & 11.67 & 18.93 & 17.44 & 28.62 & 28.16 \\
$\mathrm{~Pb}$ & 26.31 & 39.23 & 20.26 & 27.39 & 22.16 & 11.47 \\
\hline
\end{tabular}

The RSD values (Table 2) ranged from 5 to 40 independently of the degree of dilution of the solution prior to analysis. The highest RSD values were found for determination of $\mathrm{Pb}$ content directly in the post-digestion solutions, and the lowest values were for $\mathrm{Cu}$ determination in the solutions with the highest dilution, suggesting that there was significant effect of material heterogeneity on the uncertainty of determining the content of the different elements. The effect of PCB material heterogeneity on the uncertainty of the analysis results may possibly be moderated by increasing the PCB amount in the digestion process. Considering the recommendations of the manufacturer of the MW digestion system, the maximum weight of a sample for digestion can be $0.5 \mathrm{~g}$, and element content determined would be taken as the average of contents from two parallel digestions. The use of $0.5 \mathrm{~g}$ PCB material for digestion was not possible in our experiments, because unfavourable phenomena (explosions as a result of increased pressure within the closed vessel due to the inhomogeneity of sample) caused deformation and damage to the vessels.

In the next series of experiments, we compared the average content of the elements calculated from the four contents determined in the four post-digestion solutions obtained using method A1 $(\mathrm{A} 1-4 \times)$ with the content determined in the single solution containing the elements released from four replicates of digestion method $\mathrm{A} 1(\mathrm{~A} 1 \times 4)$. This experiment was also repeated by applying ten repeats of the A1 method. Figure 5 shows the content of elements determined in this series of experiments.

While the contents of the elements determined from four repeated digestions, i.e., $1.0 \mathrm{~g}$ of the sample, were significantly different for the two methods of evaluation (Figure 5a), in the case of the application of 10 repeated digestions, i.e., $2.5 \mathrm{~g}$ of the sample, these differences were minimal (Figure 5b).

In the solid residue after digestion using US EPA Method 3052 (method A1, Figure 6b), new formations were observed that were not present in the original sample (Figure 6a). These new formations may have originated in the presence of nitric acid as a result of the passivation of some metals by a layer of stable oxides (e.g., $\mathrm{Al}, \mathrm{Ca}, \mathrm{Cr}$ and $\mathrm{Fe}$ ) or the hydrolysis of some metals to form hydroxides (Sn). The use of hydrofluoric acid could result in the formation of stable fluorides of alkaline earth metals, but also of $\mathrm{Cu}, \mathrm{Pb}$ and $\mathrm{Zn}$.

SEM analysis of the solid residue after digestion of PCB material using Method A1 revealed marked diversity in shape and size of particles (Figure 7a). Local chemical analysis of the solid surface using the EDX method confirmed the presence of fibrous material (Figure 7b, spectrum 5) that, considering the higher content of non-metallic elements, probably corresponds to non-decomposed organic matter. Element concentration on the different particle surfaces (Figure 7a) is given in Table 3. It is evident, from Table 3, that the presence of Fe was confirmed in the all analysed sites. $\mathrm{Cu}$ was found only in some sites (Figure 7, spectrum 6, 7 and 9). F, O, Ca and Mg were found on the all investigated sites. Presence of $\mathrm{Al}$ and $\mathrm{Br}$ was confirmed almost on the all sites. 


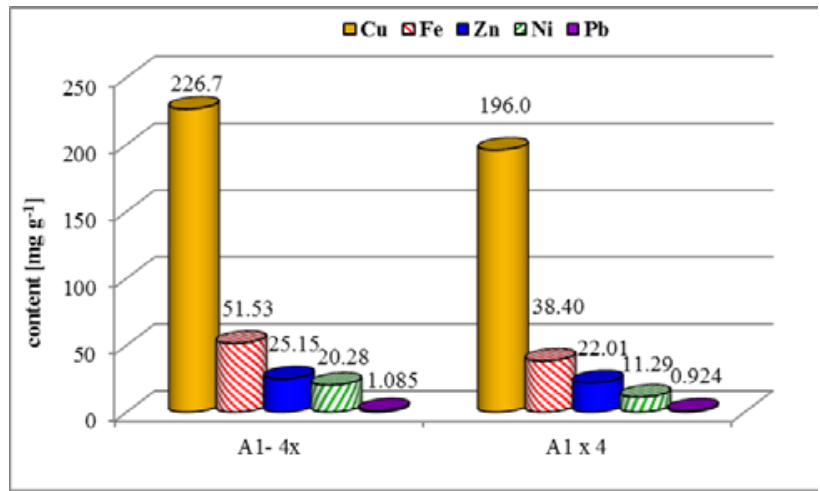

(a)

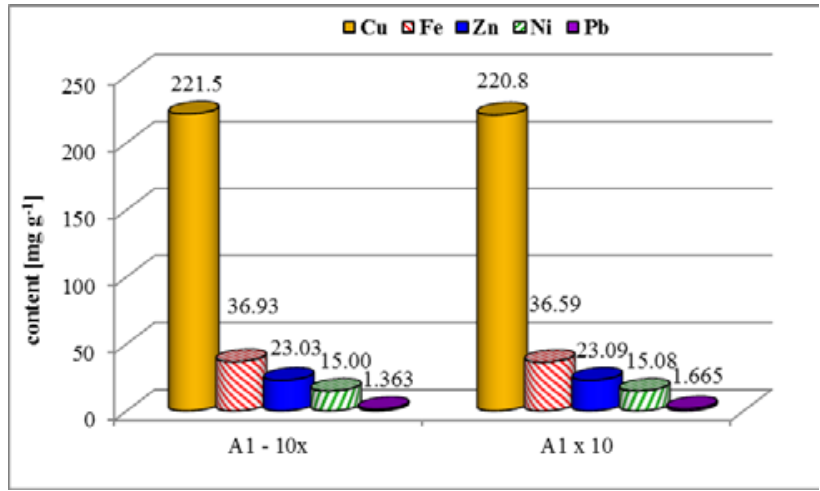

(b)

Figure 5. Content of $\mathrm{Cu}, \mathrm{Fe}, \mathrm{Zn}, \mathrm{Ni}$ and $\mathrm{Pb}$ obtained using method $\mathrm{A} 1$ expressed as (a) average of four contents from four replicates of digestion $(A 1-4 \times)$ vs. content in the single solution from four replicates of digestion $(\mathrm{A} 1 \times 4),(\mathbf{b})$ average of 10 contents from 10 replicates of digestion $(\mathrm{A} 1-10 \times)$ vs. content in the single solution from 10 replicates of digestion $(\mathrm{A} 1 \times 10)$.

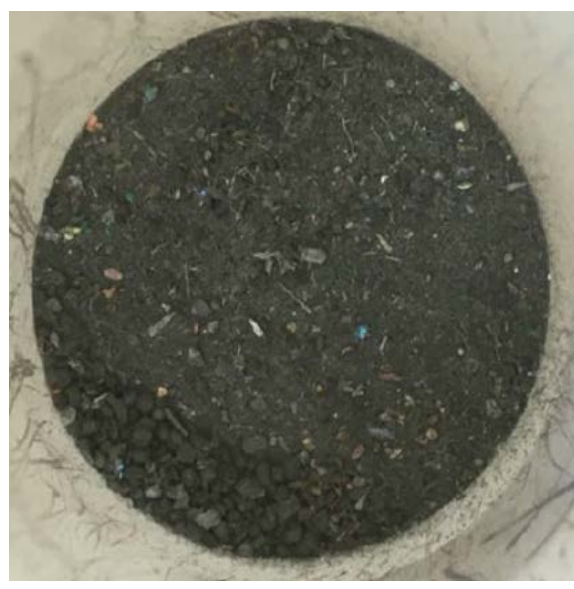

(a)

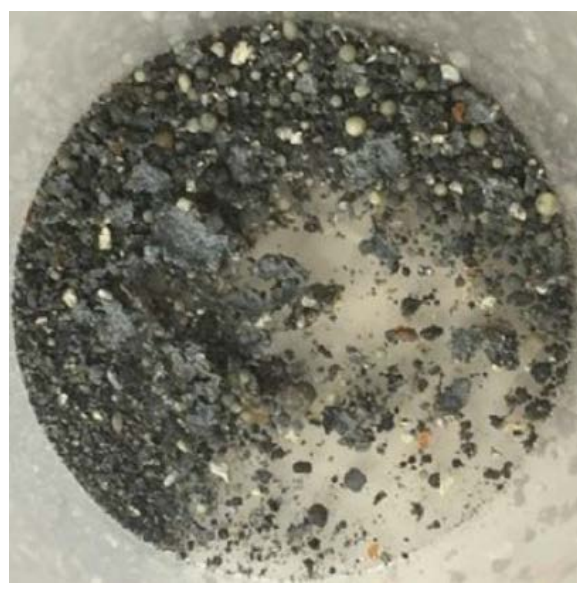

(b)

Figure 6. Images of (a) PCB analytical sample and (b) solid residue after digestion with United States Environmental Protection Agency (US EPA 3052) (method A1) (1.0:2.5, photos taken by author). 


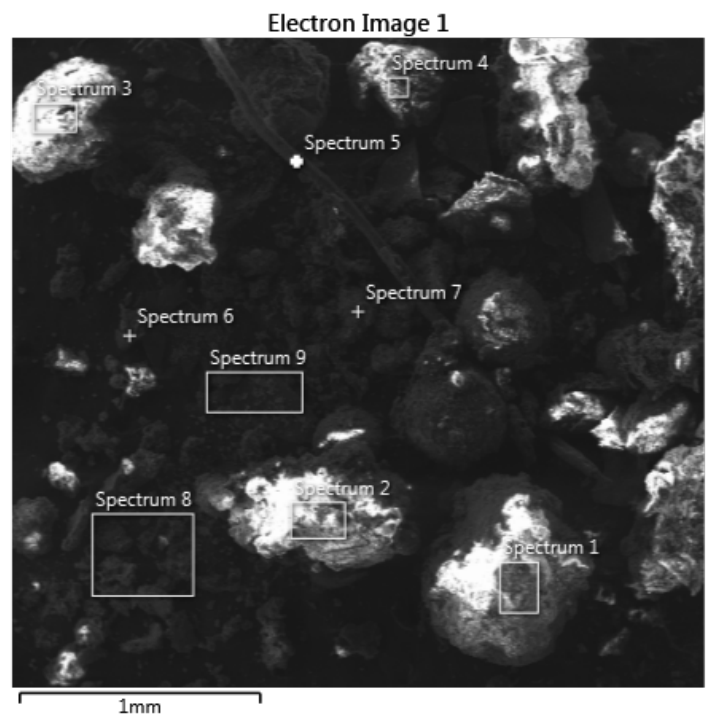

(a)

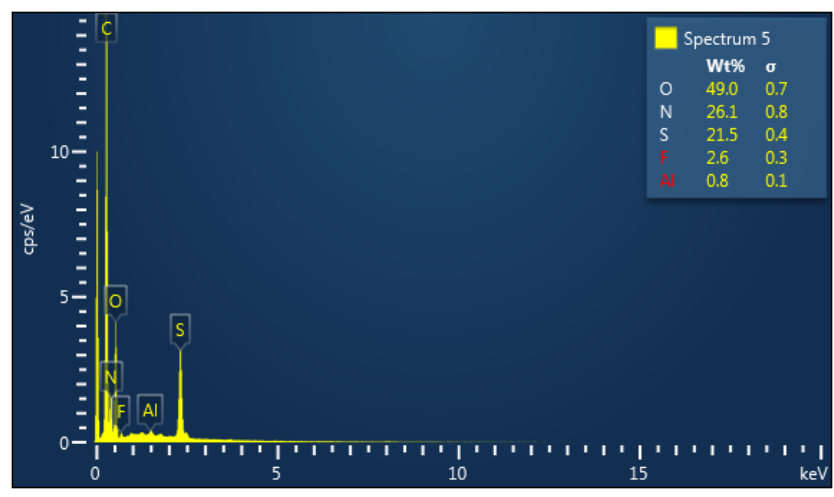

(b)

Figure 7. (a) SEM images of solid residue after digestion with US EPA method 3052; (b) chemical composition of specific particle surface material.

Table 3. Results of surface analysis of selected sites and elements.

\begin{tabular}{ccccccccc}
\hline Spectrum & \multicolumn{8}{c}{ Element [wt\%] } \\
\hline & F & Br & O & Al & Ca & Mg & Fe & Cu \\
\hline 1 & 38.3 & 7.4 & 35.0 & 9.3 & 3.1 & 4.0 & 1.8 & - \\
2 & 32.8 & 7.8 & 40.1 & 8.2 & 2.9 & 4.1 & 1.6 & - \\
3 & 16.9 & 38.6 & 29.8 & - & 5.1 & 3.1 & 4.6 & - \\
4 & 38.2 & - & 40.4 & 8.9 & 3.7 & 5.0 & 1.6 & - \\
6 & 9.1 & 21.9 & 25.7 & - & 20.2 & 2.8 & 11.3 & 3.9 \\
7 & 29.6 & 7.1 & 15.1 & 13.5 & 6.0 & 10.4 & 2.3 & 1.0 \\
8 & 19.8 & 24.7 & 28.0 & 5.9 & 5.2 & 4.2 & 2.6 & - \\
9 & 33.5 & - & 19.9 & 7.5 & 16.1 & 5.3 & 8.9 & 7.6 \\
\hline
\end{tabular}

Solid residue after decomposition in HF is probably created of florides, mainly $\mathrm{Ca}$ and $\mathrm{Mg}$, respectively, formed from unreacted HF. The oxygen in the residue is probably in the form of $\mathrm{Al}$, Fe and $\mathrm{Ca}$ oxides. The $\mathrm{HNO}_{3}$ used in the decomposition mixture caused the formation of a layer of stable oxides of the given metals (passivation). Bromides were re-formed from $\mathrm{Br}$ (flame retardant), which was released into solution upon decomposition. The presence of $\mathrm{Na}(1-2.5 \mathrm{wt} \%), \mathrm{S}(1-3.5 \mathrm{wt} \%)$, $\mathrm{Cl}(0.6-1.5 \mathrm{wt} \%)$ was found in some analyzed sites. It can be assumed that the presence of $\mathrm{Br}$ and $\mathrm{Cl}$ in 
the solid residue may be due to incomplete decomposition of the organic material (plastics) contained in the WPCBs. In addition to the mentioned elements, the presence of Ag was detected in the analyzed sites (7 and 8). At site 7, it was detected even up to $7.4 \mathrm{wt} \%$ of $\mathrm{Ag}$.

\section{Conclusions}

The choice of the most suitable digestion procedure was problematic because of the heterogeneity of the PCB material, incompleteness of digestions and unfavorable accompanying phenomena. The presence of $\mathrm{Fe}, \mathrm{Ca}, \mathrm{Al}$ and $\mathrm{O}$ in the solid residues after decomposition confirms incomplete digestion due to the formation of a stable oxide layer by the action of conc. $\mathrm{HNO}_{3}$ [21]. The presence of $\mathrm{Ca}, \mathrm{Mg}, \mathrm{Cu}$ and $\mathrm{F}$ may indicate the formation of stable insoluble fluorides as a result of the reaction with conc. HF [21]. The problem of the formation of insoluble fluorides could be eliminated by the addition of $\mathrm{H}_{2} \mathrm{SO}_{4}, \mathrm{HClO}_{3}$ or $\mathrm{HClO}_{4}$. Mentioned unfavorable phenomena can lead to the incomplete release of the metals of interest into the solution or to their re-sorption to the surface of the emerging new forms (fluorides, oxides).

In addition to the incomplete digestion of the metal components, the organic material was not completely digested too. It could be supported by the addition of a strong oxidizing agent, e.g., $\mathrm{H}_{2} \mathrm{O}_{2}$.

For elimination of the effect of WPCBs material heterogeneity on the analysis results' uncertainty, it would be best to enhance the sample amount, which is possible through integration of the residues after ten digestions into one solution. This solution corresponds to the recommended $2.5 \mathrm{~g}$ sample for digestion.

Despite the effort to improve the original US EPA method (extending the digestion time, adding the 2nd digestion step, adding $\mathrm{HCl}$, or excess of decomposing agents), it has been shown that the original US EPA Method 3052 seems to be the most effective procedure for releasing $\mathrm{Cu}, \mathrm{Fe}, \mathrm{Ni}$ and $\mathrm{Zn}$.

Author Contributions: Conceptualization, D.R.; methodology, D.R.; formal analysis, D.R., S.R. and V.M.; investigation, D.R., V.M., M.L. and R.S.; resources, M.L.; writing-original draft preparation, D.R.; writing-review and editing, S.R. and V.M. visualization, S.R.; project administration, S.R.; funding acquisition, S.R. All authors have read and agreed to the published version of the manuscript.

Funding: This research was funded by Scientific Grant Agency VEGA, grant number 1/0631/17.

Conflicts of Interest: The authors declare no conflict of interest. The funders had no role in the design of the study; in the collection, analyses, or interpretation of data; in the writing of the manuscript, or in the decision to publish the results.

\section{References}

1. Maragkos, K.G.; Hahladakis, J.N.; Gidarakos, E. Qualitative and quantitative determination of heavy metals in waste cellular phones. Waste Manag. 2013, 33, 1882-1889. [CrossRef]

2. Kaya, M. Recovery of metals and nonmetals from electronic waste by physical and chemical recycling processes. Waste Manag. 2016, 57, 64-90. [CrossRef] [PubMed]

3. Ghosh, B.; Ghosh, M.K.; Parhi, P.; Mukherjee, P.S.; Mishra, B.K. Waste printed circuit boards recycling: An extensive assessment of current status. J. Clean. Prod. 2015, 94, 5-19. [CrossRef]

4. Das, S.; Ting, Y.-P. Evaluation of wet digestion methods for quantification of metal content in electronic scrap material. Resources 2017, 6, 64. [CrossRef]

5. Yamane, L.H.; de Moraes, V.T.; Espinosa, D.C.R.; Tenório, J.A.S. Recycling of WEEE: Characterization of spent printed boards from mobile phones and computers. Waste Manag. 2011, 31, 2553-2558. [CrossRef] [PubMed]

6. Kasper, A.C.; Berselli, G.B.T.; Freitas, B.D.; Tenório, J.A.S.; Bernardes, A.M.; Veit, H.M. Printed wiring boards for mobile phones: Characterization and recycling of copper. Waste Manag. 2011, 31, 2536-2545. [CrossRef]

7. Priya, A.; Hait, S. Qualitative and quantitative metals liberation assessment for characterization of various waste printed circuit boards for recycling. Environ. Sci. Pollut. Res. 2017, 24, 27445-27456. [CrossRef]

8. Bizzo, W.A.; Figueiredo, R.A.; de Andrade, V.F. Characterization of printed circuit boards for metal and energy recovery after milling and mechanical separation. Materials 2014, 7, 4555-4566. [CrossRef] [PubMed] 
9. Le, H.-L.; Yamasue, E.; Okumura, H.; Ishihara, K.N. MEMRECS-A sustainable view for metal recycling from waste printed circuit boards. J. Environ. Prot. 2013, 4, 803-810. [CrossRef]

10. Ogunniyi, I.O.; Vermaak, M.K.G.; Groot, D.R. Chemical composition and liberation characterization of printed circuit board comminution fines for benefication investigations. Waste Manag. 2009, 29, 2140-2146. [CrossRef]

11. Laubertova, M.; Malindzakova, M.; Rosova, A.; Trpcevska, J. Material flow model of electronic waste sampling and assaying. Przem. Chem. 2016, 95, 1390-1394.

12. Sundqvist, R. E-Scrap Fundamentals. 2012. Available online: http://www.boliden.com/globalassets/ investor-relations/reports-and-presentations/capital-markets-day/2012/cmd/2-e-scrap-fundamentalsroger-sundqvist-general-manager-boliden-ronnskar.pdf (accessed on 11 July 2020).

13. Umicore Precious Metals Refining. 2009. Available online: http://www.umicore.com/storage/migrate/ 2009sept_PMR.pdf (accessed on 12 July 2020).

14. Recycling Aurubis. 2013. Available online: http://www.aurubis.com/binaries/content/assets/aurubis-en/ dateien/product-documents/recycling-brochure_2013_eng_doppelseitig.pdf (accessed on 10 July 2020).

15. ALS Scandinavia. Available online: http://www.alsglobal.se (accessed on 14 July 2020).

16. Vegliò, F.; Birloaga, I. Waste Electrical and Electronic Equipment Recycling, 1st ed.; Elsevier: Amsterdam, The Netherlands, 2018.

17. Khaliq, A.; Rhamdhani, M.A.; Brooks, G.; Masood, S. Metal extraction processes for electronic waste and existing industrial routes: A review and australian perspective. Resources 2014, 3, 152-179. [CrossRef]

18. Ramanathan, T.; Ting, Y.-P. Selection of wet digestion methods for metal quantification in hazardous solid wastes. J. Environ. Chem. Eng. 2015, 3, 1459-1467. [CrossRef]

19. Priya, A.; Hait, S. Toxicity characterization of metals from various waste printed circuit boards. Process Saf. Environ. Prot. 2018, 116, 74-81. [CrossRef]

20. Priya, A.; Hait, S. Comprehensive characterization of printed circuit boards of various end-of-life electrical and electronic equipment for benefication investigation. Waste Manag. 2018, 75, 103-123. [CrossRef] [PubMed]

21. Krakovská, E.; Kuss, H.-M. Digestions in Analytical Chemistry (In Slovak), 1st ed.; Vienala: Košice, Slovakia, 2001.

Publisher's Note: MDPI stays neutral with regard to jurisdictional claims in published maps and institutional affiliations.

(C) 2020 by the authors. Licensee MDPI, Basel, Switzerland. This article is an open access article distributed under the terms and conditions of the Creative Commons Attribution (CC BY) license (http://creativecommons.org/licenses/by/4.0/). 